\title{
Sustainable Mixtures of TDA and Class A Gravel
}

\author{
Mohammad Ashari, Hany El Naggar \\ Department of Civil and Resource Engineering \\ Dalhousie University, Halifax, Canada \\ m.ashari@dal.ca; hany.elnaggar@dal.ca
}

\begin{abstract}
Stockpiling or landfilling discarded tires poses major problems for the environment. In order to address these problems, several methods are currently employed to reuse discarded tires. One of these methods, which is gaining popularity, is to shred discarded tires into tire derived aggregates (TDA) and use them in civil engineering purposes such as backfill material for embankments or foundations. Despite the recent popularity of TDA, the experimental research to identify its geotechnical properties is limited or non-existent. Furthermore, most of the research done was either with small size TDA particles, to accommodate the readily available small-scale triaxial machines, or used direct shear apparatus which has limitations such as predefined failure surface and limited control over confinement pressure. In this study, the physical properties of five different TDA-gravel mixtures were evaluated using a large-scale triaxial machine. The TDA used in this study was the same size TDA used in civil engineering projects. All the tests were conducted according to ASTM standards. Finally, the results of deviatoric stress and volumetric strain vs axial strain for each mixture was reported and discussed.
\end{abstract}

Keywords: Triaxial Test, TDA, Tire Derived Aggregates, Tire Shred, Gravel, Deviatoric Stress, Volumetric Strain.

\section{Introduction}

Advances in the industry and growing population has led to an increase in the amount of scrap tires produced every year. In the year 2015, Canadians disposed of 37 million tires [1] while 250 million scrap tires were disposed of in the US [2]. Stockpiling scrap tires can be dangerous. Stockpiles can be a potential fire hazard or a breeding ground for rats, mice or mosquitos [3]. Reusing scrap tires prevents these environmental risks, averts depletion of the natural resources and gives them ecological value. The top three applications of scrap tires are tire-derived fuels, ground rubber feed and civil engineering projects respectively. Compared to the other applications, using scrap tires in civil engineering projects has recently shown the most amount of growth [2]. To use scrap tires in civil engineering applications, they must be shredded into TDA first. Despite the recent growth in TDA usage, there is not enough experimental research to identify its mechanical properties. Additionally, most of the research done on TDA is not representative of the TDA used in civil engineering applications. The larger particle size of the TDA used by the industry is difficult for researchers to use in experiments. In addition, the existence of steel belts in TDA can further complicate experiments. For these reasons, in the past, most researchers either removed the steel belts and shredded the TDA to smaller sizes or ran other types of less accurate tests on TDA.

Many researchers have tried to use direct shear tests to evaluate the geotechnical properties of TDA and TDA mixed with soil. Foose et al. [4] conducted direct shear tests on different mixtures of dry sand and shredded tires. In their study, the dried sand was mixed with three different categories of length of wire reinforced tire shreds: smaller than $5 \mathrm{~cm}, 5$ to 10 $\mathrm{cm}$ and 10 to $15 \mathrm{~cm}$. The tests were conducted for $10 \%$ and $30 \%$ tire shred content by volume and they used both vertical and random orientations of tire shreds. For their tests, they used a large-scale direct shear machine and reported the maximum shear strength, vertical displacement and friction angles of their specimens. Tatlisoz et al. [5] used a large-scale direct shear machine and tested different compositions. The lengths of tire chips used in their experiment were between 30 to $110 \mathrm{~mm}$. The compositions consisted of pure tire chips, sand, silty sand and mixtures of tire chips with either sand or silty sand at 10, 20 and 30 percent by volume. They reported the amounts of maximum shear strength, cohesion and the internal friction angle for their specimens. To investigate the geotechnical properties of tire shreds and tire shreds mixed with a cohesive clayey soil, Cetin et al. [5] performed direct shear tests on tire shreds and their mixtures with different composition of the cohesive soil. The tire shreds that they used were free of steel belts and fine in size with the maximum 
size of $4.75 \mathrm{~mm}$. To study the effect of TDA particle size on shear strength and stiffness of TDA/sand mixtures, El Naggar et al. [6] performed a series of large-scale direct shear tests on different compositions of sand and TDA mixtures. Their results show that mixtures with coarser TDA content possess higher amounts of stiffness and shear strength.

Some researchers used triaxial tests to study TDA and TDA/soil mixtures. Masad et al. [7] used a small-scale triaxial machine to evaluate the engineering properties of tire/soil mixtures. The diameter of their samples was 71.1 $\mathrm{mm}$, and the maximum tire chips size that they used was $4.75 \mathrm{~mm}$. The steel belts were not present in their experiment. They reported the friction angle and cohesion of their compositions. To investigate the stress versus strain relationship and the strength of tire chips mixed with sand, Lee et al. [8] conducted a triaxial testing program. In their experiment, they used tire chips with a maximum size of $30 \mathrm{~mm}$ with no exposed steel belts. They reported the mechanical properties of their composition. Utilizing a large scale triaxial apparatus, Zornberg et al. [9] performed a total of 15 consolidated drained triaxial tests with samples made of tire shred- soil mixtures. In their experiment, they used rectangular shaped tire shreds from which the steel had been removed. The diameter of their specimens were 6 inches, and they used three confining pressures of 48.3, 103.5 and $207 \mathrm{kPa}$ and reported the results. Noorzad and Raveshi [10] performed a series of consolidated drained triaxial tests on mixtures of sand and tire crumbs. The TDA used was devoid of steel and with a maximum particle size of about $5 \mathrm{~mm}$. They reported the amount of cohesion and the angle of internal friction for their mixtures.

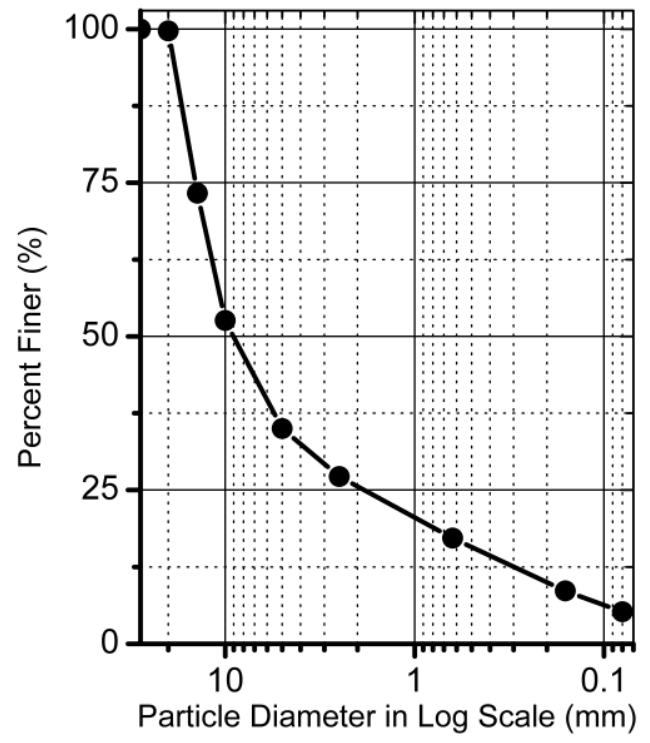

(a) Gravel gradation

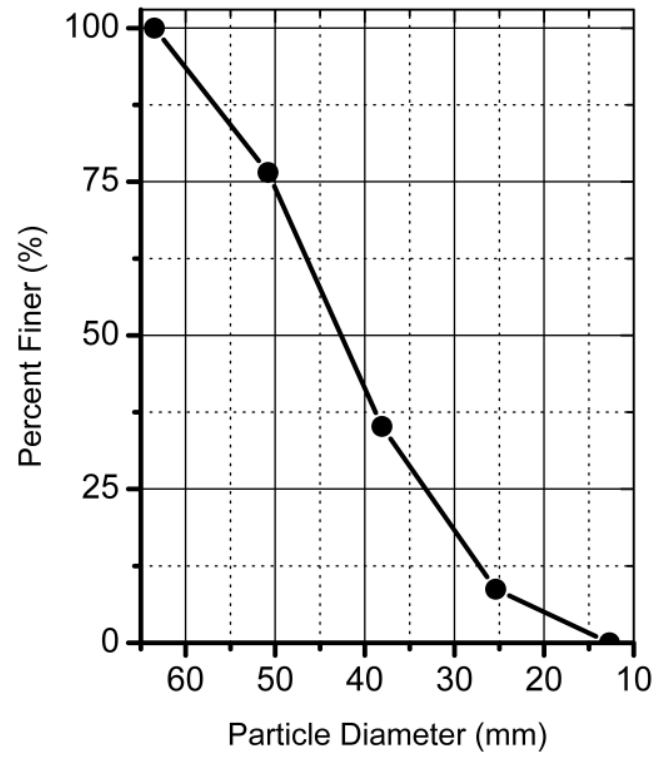

(b) TDA gradation

Fig. 1: Particle size distributions of gravel and TDA.

\section{Material}

The gravel and TDA used in this experiment were graded according to the ASTM standard. The gravel used in the experiment was type 1 gravel per Nova Scotia Transportation and Public Works Standard Specification which is equivalent to the commonly known Class A gravel. The particle size distribution of the gravel is shown in Fig. 1a The TDA used was shredded and manufactured by Halifax C\&D Recycling Ltd from discarded passenger tires. The TDA was tested for size gradation and metal fragments, and it complied with Type A TDA per ASTM D6270-08 standard. Fig. 1b depicts the TDA particle size distribution used in this experiment. As evident from the figure, the size of the TDA particles was in the range of 13-63 mm. To protect the triaxial membrane, the protruding part of the steel wires were removed from the TDA particles. Removing the protruding steel can diminish the ability of TDA particles to 
interlock during the test which can decrease the cohesion of the samples. Fig. 2 represents the results of the optimum water content test for the gravel in accordance with ASTM D698-12.

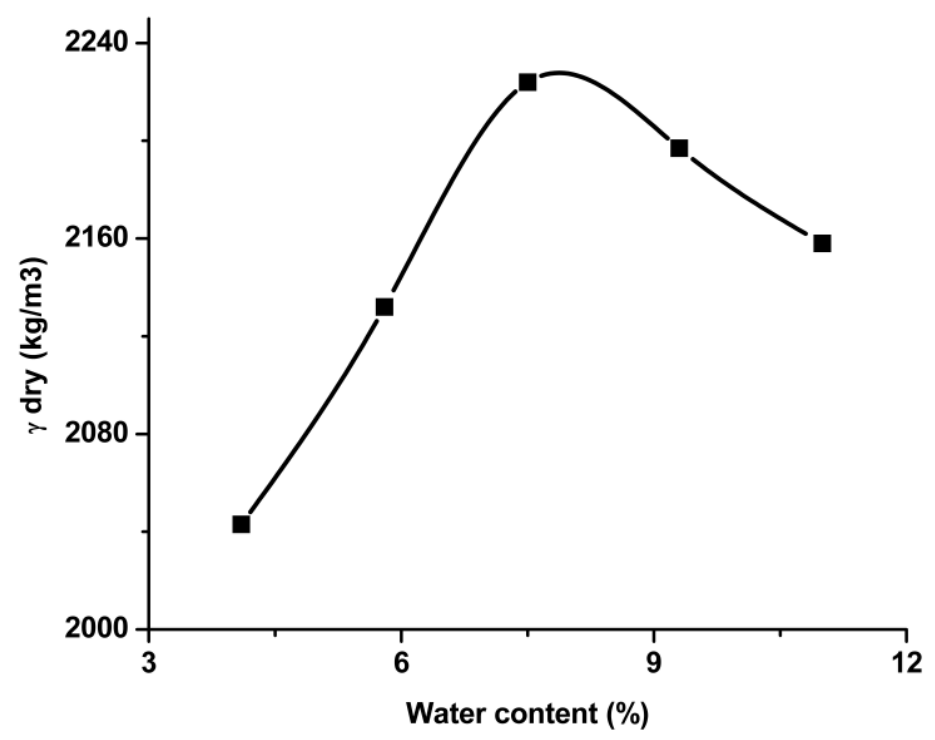

Fig. 2: Optimum water content of Gravel.

\section{Triaxial Test Apparatus}

All triaxial tests in this research were conducted using a large-scale triaxial apparatus capable of testing samples of $152 \mathrm{~mm}$ in diameter. In order to apply the axial loading an Instron 8501 hydraulic load frame, capable of recording the load and displacement at a frequency of $20 \mathrm{~Hz}$, was used. Two GDS Advanced Pressure Volume Controllers were utilized to record the volume change of the sample and cell while keeping the pressure constant.

\section{Sample Preparation}

Five sets of samples with different compositions were prepared. Each set included three samples to be tested under three different confining pressures. The sample sets consisted of one set of pure gravel as the reference case and four different compositions of gravel and TDA as shown in Table 1. Before compaction, water was added to the gravel to reach optimum moisture content. All samples were compacted with the compaction energy of 600 kilojoules per cubic metre using a standard Proctor.

Table 1: Mixture properties.

\begin{tabular}{|c|c|c|c|}
\hline Composition & $\begin{array}{c}\text { TDA (\%) } \\
\text { by weight }\end{array}$ & $\begin{array}{c}\text { Gravel (\%) } \\
\text { by weight }\end{array}$ & $\begin{array}{c}\text { Dry density } \\
\left(\mathrm{kg} / \mathrm{m}^{3}\right)\end{array}$ \\
\hline Gravel & 0 & 100 & 2108 \\
\hline M5 & 5 & 95 & 1815 \\
\hline M10 & 10 & 90 & 1749 \\
\hline M20 & 20 & 80 & 1593 \\
\hline M30 & 30 & 70 & 1483 \\
\hline
\end{tabular}

\section{Testing Procedure}

All the tests were performed in consolidated drain condition according to ASTM D7181-11. Each sample set was tested three times for three confining pressures of $50 \mathrm{kPa}, 100 \mathrm{kPa}$ and $200 \mathrm{kPa}$. According to the standard, tests were 
performed in three stages of saturation, consolidation and axial loading. During the saturation stage, the parameter of pore pressure B was measured to make sure that the amount of air bubbles in the sample was insignificant. Throughout the consolidation stage, the amount of volume change in the sample was recorded and plotted against time. Later this plot was used to calculate the maximum rate of axial loading per ASTM standard. After the completion of the consolidation stage, the samples were subjected to axial loading. During axial loading, the amount of load, deformation and volume change inside the sample and the cell were recorded. Later these values were used to calculate and draw the deviatoric stress versus strain curves.

\section{Results and Discussions}

As mentioned, for each sample during the axial loading, the volume changes inside the sample were recorded. Using these changes in volume, the amount of volumetric strain of the sample was calculated and plotted against the axial strain. Fig. 3 compares the amount of volumetric strain of the samples under confining pressure of 100kPa. As shown in the figure, the volumetric strain in the samples with a lower amount of TDA resembles the gravel which is to be expected. On the other hand, as the percentage of TDA increases, this resemblance diminishes. Additionally, it was observed in the experiment, in samples with a lower amount of TDA, confining pressure influences volumetric strain. However, this influence reduces as the percentage of TDA increases. This can be seen more prominently in M30 samples which behave similar to pure TDA sample.

The results of deviatoric stress versus strain for all the sample sets at confining pressures of $50 \mathrm{kPa}, 100 \mathrm{kPa}$ and $200 \mathrm{kPa}$ are compared in Fig. 4. The ASTM correction for changes in length and volume were applied when plotting the graphs. It can be seen that for all samples except M30 after the deviatoric stress reaches a peak amount, it starts decreasing gradually. In other words, as the percentage of TDA increases, the sample behaviour shifts from pure gravel behaviour towards pure TDA behaviour which is to be expected. It is possible that if the test were continued beyond the strain of $20 \%$, the deviatoric stress would have reached a peak maximum but continuing the test was beyond the capabilities of the triaxial apparatus. Even reaching these high amounts of strain required tweaking the triaxial machine and extending the axial loading shaft. It is evident that as the percentage of TDA increases, the curves become less steep. That is to say, increase in the percentage of TDA reduces the stiffness of the samples. In addition, the increase in the percentage of TDA increases the strain that the peak maximum deviatoric stress occurs in. Compared to the results of other TDA mixtures, it seems that the M10 has a higher amount of peak maximum deviatoric stress in all three confining pressures.

Table 2 provides the values for cohesion and the angle of internal friction for different mixtures based on MohrCoulomb failure criterion. These values were calculated using the ultimate limit state. The table suggests that by adding TDA to gravel, the angle of internal friction decreases while the cohesion increases.

Table 2: Values of cohesion and the angle of internal friction.

\begin{tabular}{|c|c|c|}
\hline Composition & Cohesion $(\mathrm{kPa})$ & $\begin{array}{c}\text { The angle of internal } \\
\text { friction }(\varphi)\end{array}$ \\
\hline Gravel & - & 49 \\
\hline M5 & 62 & 41 \\
\hline M10 & 68 & 42 \\
\hline M20 & 51 & 42 \\
\hline M30 & 109 & 36 \\
\hline
\end{tabular}




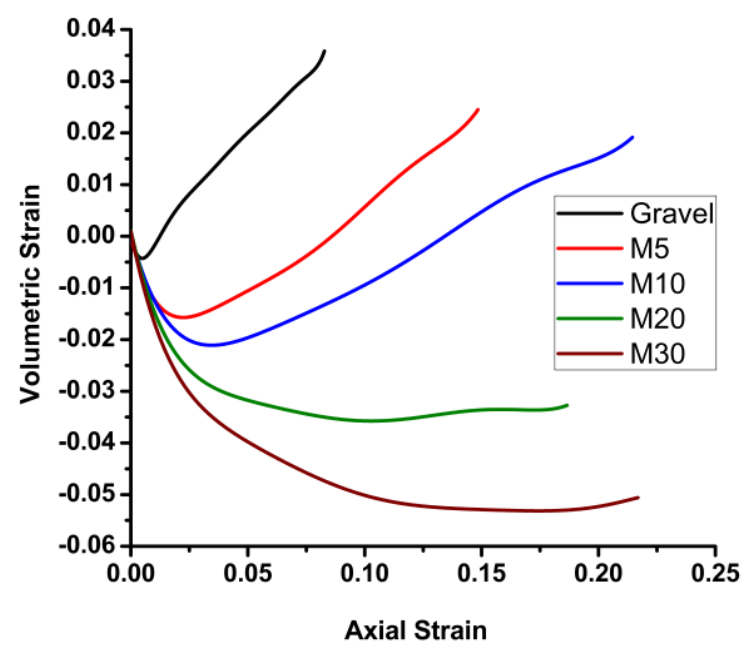

Fig. 3: Volumetric strain of the samples under $100 \mathrm{kPa}$ confining pressure.

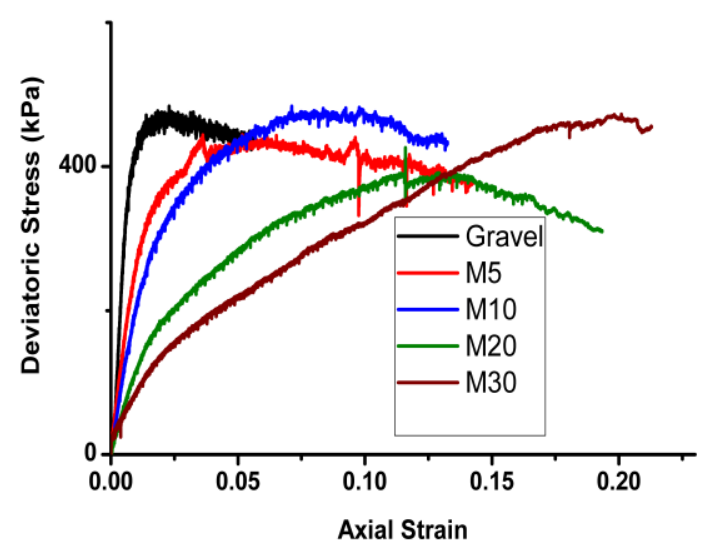

(a) $50 \mathrm{kPa}$

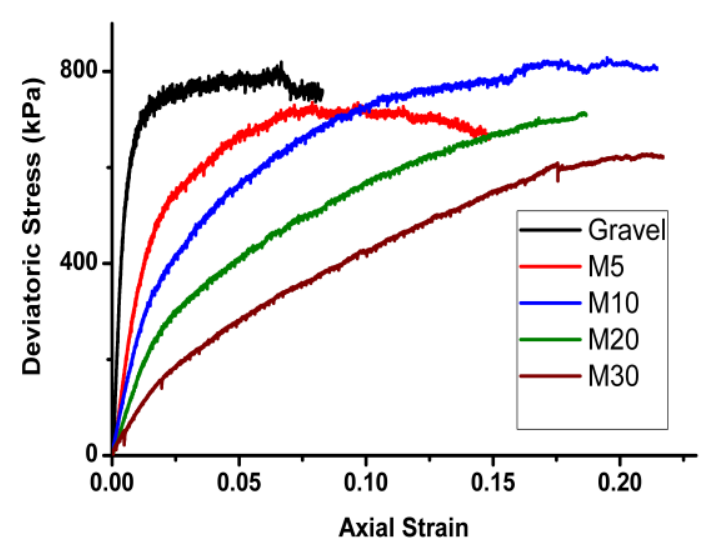

(b) $100 \mathrm{kPa}$

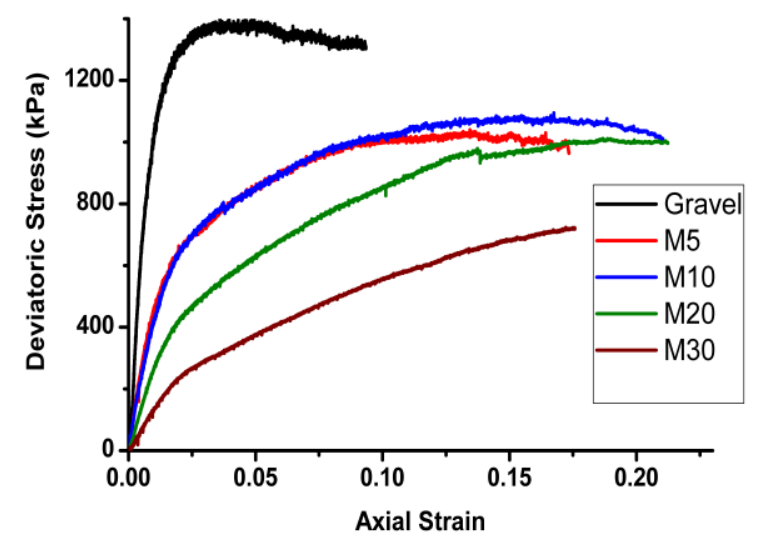

(c) $200 \mathrm{kPa}$

Fig. 4: Comparison of deviatoric stress vs. strain in each confining pressure. 


\section{Conclusions}

In this study, a series of triaxial tests were performed on different mixture compositions of TDA and gravel. The gravel used in this study was Class A gravel. The TDA used in the study was TDA type A per ASTM D6270-08 which is the size used in most civil engineering projects. Sample sets were prepared with varying percentages of TDA. Each sample set was tested in three different confining pressures, and the results of deviatoric stress and volumetric strain versus axial strain were depicted. Finally, the values of cohesion and the angle of internal friction for each mixture composition were presented. Based on the results of the conducted testing program, the following conclusions can be drawn:

1- As the percentage of TDA in compositions increases, the volumetric strain of the samples changes its behaviour;

2- Increase in the percentage of TDA leads to increases in the strain that the maximum stress occurs in;

3- The sample with 10\% TDA exhibits higher amounts of maximum deviatoric stress compared to the other TDA mixtures;

4- Sample with lower amounts of TDA have higher strength compared to samples with higher amounts of TDA;

5- Adding TDA to gravel increases the cohesion while decreases the angle of internal friction.

\section{Acknowledgements}

The authors acknowledge the financial support provided by the Natural Sciences and Engineering Council of Canada (NSERC), and the generosity of our research collaborator Halifax C\&D Recycling Limited for the donation of all the TDA materials used in this project.

\section{References}

[1] Zalando, Annual Report 2016, Zalando Corp. website, p. 175, 2016.

[2] Rubber manufacturers association, "2015 U. S. Scrap Tire Management Summary U. S. Scrap Tire Disposition 2015," no. May 2016, pp. 1-19, 2016.

[3] M. Ashari, H. El Naggar, and Y. Martins, "Evaluation of the physical properties of TDA-sand mixtures," in GeoOttawa 2017, 2017.

[4] G. J. Foose, C. H. Benson, and P. J. Bosscher, "Sand Reinforced with Shredded Waste Tires," J. Geotech. Eng., vol. 122 , no. 9 , pp. 760-767, 1996.

[5] N. Tatlisoz, T. B. Edil, and C. H. Benson, "Interaction between Reinforcing Geosynthetics and Soil-Tire Chip Mixtures," J. Geotech. Geoenvironmental Eng., vol. 124, no. 11, pp. 1109-1119, 1998.

[6] H. El Naggar, P. Soleimani, and A. Fakhroo, "Strength and Stiffness Properties of Green Lightweight Fill Mixtures," Geotech. Geol. Eng., vol. 34, no. 3, pp. 867-876, 2016.

[7] E. Masad, R. Taha, C. Ho, and T. Papagiannakis, "Engineering Properties of Tire/Soil Mixtures as a Lightweight Fill Material," Geotech. Test. Journal, vol. 19, pp. 297-304, 1996.

[8] J. H. Lee, R. Salgado, A. Bernal, and C. W. Lovell, "Shredded Tires and Rubber-Sand as Lightweight Backfill," J. Geotech. Geoenvironmental Eng., vol. 125, no. February, pp. 132-141, 1999.

[9] J. G. Zornberg, A. R. Cabral, and C. Viratjandr, "Behaviour of tire shred - sand mixtures," Can. Geotech. J., vol. 41, no. 2, pp. 227-241, 2004.

[10] R. Noorzad and M. Raveshi, "Mechanical Behavior of Waste Tire Crumbs-Sand Mixtures Determined by Triaxial Tests,” Geotech. Geol. Eng., vol. 35, no. 4, pp. 1793-1802, 2017. 